\title{
Heterogeneous Himalayan crust using shear wave attenuation in the Pithoragarh region of Kumaon
}

\author{
A Joshi ${ }^{*}$, M Mohanty², AR Bansal ${ }^{3}$, VP Dimri ${ }^{3}$ and RK Chadha ${ }^{3}$ \\ 1 Indian Institute of Technology, Roorkee, Roorkee 247 667, Uttarakhand, INDIA \\ 2 Department of Science and Technology, Government of India, New Delhi, INDIA \\ 3 National Geophysical Research Institute, Uppal Road, Hyderabad, INDIA \\ * For correspondence,email: anushijos@yahoo.co.in
}

Pithoragarh district of Uttarakhand Himalaya, which lies in the border region of India and Nepal, falls in the seismically active zone of the seismic zoning map of India. Under a major DST sponsored project a network of eight strong motion stations has been installed in this region since March 2006. This paper presents a method of finding shear wave quality factor ' $Q_{\beta}(f)$ ' from strong motion data recorded by this network. The method used for this study is based on modified technique, given by Joshi (2006). Data of local noise recorded at various stations have been utilized for the purpose of site survey and average value at each station is used for correcting the accelerograms for site amplifications. Based on availability of data, hypocentral parameters and clear S phases from horizontal component of 37 strong motion records from six stations have been used for in this work. The output of this inversion gives $Q_{\beta}(f)$ relation and corner frequencies of earthquake at different stations. Low value of coefficient $(<200)$ and high frequency dependence (>.8) in the $Q_{\beta}(f)$ relationships obtained at different stations suggest that the region is seismically and tectonically active and is characterized by large number of heterogeneities. Obtained $\mathrm{Q}_{\beta}(\mathrm{f})$ are used to compute source spectrum of $\mathrm{S}$ wave from the accelerogram and are compared with theoretical Brune's source spectrum of corner frequency obtained from inversion. Comparison of source spectrum obtained from the corrected accelerograms with the theoretical Brune spectrum shows that this technique has potential to give reliable $Q_{\beta}(f)$ and source parameters of the studied earthquakes using records from single station. Using the obtained $Q_{\beta}(f)$ values at different stations at different frequencies an average $Q_{\beta}(\mathrm{f})$ relation of $50 \mathrm{f}^{1.08}$ has been obtained for Pithoragarh region of Kumaon Himalaya. Obtained relations not only explain the complexities and heterogeneities of earth crust in Himalaya, it can be used as an input for simulation of strong ground motion in this region. 